\title{
Hypothermic cardiopulmonary bypass in paramyotonia congenita: a case report
}

\author{
IJ REECE, JA KENNEDY, JA SIMPSON, KM TAYLOR \\ From the University Department of Cardiac Surgery, Glasgow Royal Infurmary, and the University \\ Department of Neurology, Institute of Neurological Sciences, Glasgow
}

Paramyotonia congenita is a non-progressive disease characterised by myotonia (failure of muscle relaxation) induced by the exposure of the affected muscles to cold. Episodes of flaccid paralysis occur and may be related to hyperkalaemic periodic paralysis. Proximal myopathy or muscular hypertrophy may occur. The condition is inherited as an autosomal dominant. ${ }^{\prime}$ Severe paralysis may occur with comparatively slight increases in plasma potassium concentration. During an attack of paralysis there is loss of potassium from muscle cells, which become depolarised.

With these biochemical and clinical features, difficulties might be anticipated in undertaking open-heart surgery in patients with this condition. This report concerns the events surrounding mitral valve replacement using hypothermia during cardiopulmonary bypass in a patient with paramyotonia congenita.

\section{Case report}

A 48-year-old woman known to be suffering from paramyotonia congenita was admitted to Mearnskirk Hospital in Glasgow in May 1981 for mitral valve replacement. She had progressive dyspnoea to grade III and on the New York Heart Association scale was in functional grade IIIII. She was taking digoxin and diuretics. There was no history of orthopnoea, nocturnal dyspnoea, or angina. She had previously had an episode of endogenous depression. On admission her heart was in controlled atrial fibrillation. The physical findings were characteristic of dominant mitral stenosis and this was confirmed by echocardiography and cardiac catheterisation. Her mean resting pulmonary artery pressure was $60 \mathrm{~mm} \mathrm{Hg}$. She displayed the typical features of paramyotonia congenita with periodic stiffness of the hands and face, especially after exertion, and rigidity of muscles precipitated by cold. If, for example, she tried to eat ice cream her buccal muscles and ton gue would become paralysed.

Premedication was with $10 \mathrm{mg}$ papavaretum and $0.2 \mathrm{mg}$ hyoscine. Anaesthesia was induced with intravenous thiopentone sodium $(150 \mathrm{mg})$. Droperidol $(10 \mathrm{mg})$ and fentanyl $(0.3 \mathrm{mg})$ were administered to maintain anaesthesia. The patient was paralysed with pancuronium bromide $(6 \mathrm{mg})$, intubated, and ventilated with a mixture of nitrous oxide and oxygen. After median sternotomy

Address for reprint requests: Mr KM Taylor, Department of Cardiac Surgery, Royal Infirmary, Glasgow G4 OSF.

Accepted 6 December 1982 with cannulation of the ascending aorta and right atrium, pulsatile cardiopulmonary bypass was started and the patient was cooled to $28^{\circ} \mathrm{C}$. Mitral valve replacement was carried out with a $29-\mathrm{mm}$ Björk-Shiley prosthesis, interrupted horizontal mattress sutures being used. The aortic cross-clamp time was 58 minutes and the myocardium was protected by a bolus of $1.0 \mathrm{l}$ of St Thomas's cardioplegic solution and topical hypothermia. The patient was rewarmed slowly to $37^{\circ} \mathrm{C}$ and weaned off bypass easily after a total perfusion time of 82 minutes.

The patient was returned to the intensive care unit, haemodynamically stable and responding to commands. Muscle relaxant drugs were allowed to wear off and the patient was able to breathe spontaneously and was extubated five hours after surgery, the core temperature having remained at $37^{\circ} \mathrm{C}$. Her respiration subsequently remained stable, though the arterial $\mathrm{PCO}_{2}$ rose steadily to $6 \cdot 5-8 \cdot 0$ $\mathrm{kPa}$ during the first postoperative night; by the second day it had returned to normal levels. The only apparent postoperative complication was the presence of brief episodes of sudden hypotension associated with a falling central venous pressure. The systolic pressure at times was as low as $70 \mathrm{~mm} \mathrm{Hg}$. These episodes were not prevented by a dopamine infusion at $10 \mathrm{~g} / \mathrm{kg} / \mathrm{min}$ and volume replacement and were thought to be related to alterations in the peripheral venous tone, with large changes in circulatory capacitance. The episodes abated spontaneously over the next few days and the patient was returned to the ward on the fifth postoperative day and discharged home on the ninth. When seen six weeks after surgery she was clinically well without significant cardiac symptoms and her paramyotonia congenita was unchanged.

\section{Discussion}

Paramyotonia congenita is a rare affliction and patients with this condition seldom present to the cardiac surgeon. This paper reports, we believe, the first patient with paramyotonia congenita to undergo cardiac surgery using hypothermic cardiopulmonary bypass. The use of systemic hypothermia during cardiac surgery is well established and undoubtedly beneficial, ${ }^{2}$ especially where cold potassium cardioplegia and topical cold saline are used for myocardial protection. The use of controlled hypothermia to $28^{\circ} \mathrm{C}$ on bypass, with adequate rewarming to $37^{\circ} \mathrm{C}$, produced no ill effects in our patient. Certainly the fact that she was breathing spontaneously five hours after return to the intensive care unit is good evidence that such a period at $28^{\circ} \mathrm{C}$ should give rise to no lasting myotonia provided that subsequent rewarming is adequate.

To prevent myotonia in the period before bypass, 
depolarising muscle relaxants were avoided and paralysis was induced with pancuronium. There were no difficulties with ventilation in this period and, although moderate hypothermia is known to potentiate all types of neuromuscular blockade ${ }^{3}$ the patient showed no abnormal requirements or sensitivity to the dose administered and was responding to commands at the end of the procedure. To avoid inducing myotonia we did not use halothane, which commonly produces postoperative shivering.

Another potential difficulty in paramyotonia congenita relates to the electrolyte shifts which may occur with haemodilution and cardiopulmonary bypass. In particular, hyperkalaemia may precipitate myotonia. ${ }^{1}$ The primary muscle defect is thought to be related to increased sodium conductance in affected muscles. An infusion of $80 \mathrm{mmol}$ (mEq) of potassium chloride in $500 \mathrm{ml} \mathrm{5 \%}$ dextrose infused at $80 \mathrm{ml} / \mathrm{h}$ was able to prevent gross fluctuations in serum potassium concentrations in this patient.

Only minimal postoperative respiratory depression was seen, with a transient rise in arterial $\mathrm{PCO}_{2}$. The major postoperative difficulty encountered was the occurrence of brief episodes of hypotension and falling central venous pressures, which were not significantly affected by volume loading or by dopamine infusion. Although the aetiology of these haemodynamic changes is not definitely known, they were possibly related to sudden changes in peripheral resistance or venous capacitance or both. The attacks proved benign, though they did increase the duration of the patient's stay in the intensive care unit.

In summary, cardiopulmonary bypass using moderate hypothermia has been undertaken safely in a patient with paramyotonia congenita. Depolarising muscle relaxants and halothane were avoided, and complete rewarming on bypass was carefully carried out. The anticipated respiratory difficulties did not occur and postoperative recovery was complete.

\section{References}

' Thrush DC, Morris CT, Salmon MV. Paramyotonia congenita: a clinical, histochemical and pathological study. Brain 1972;95:537-45.

${ }^{2}$ Utley JR, Wachtel C, Cain RB, Spaw EA, Collins JC, Stephens DB. Effects of hypothermia, hemodilution, and pump oxygenation on organ water content, blood flow and oxygen delivery, and renal function. Ann Thorac Surg 1981;31:121-33.

${ }^{3}$ Thornton RJ, Blakeney C, Feldman SA. Summary presented to the Anaesthetic Research Group. The effect of hypothermia on neuromuscular conduction. Br J Anaesth 1976;48:264.

\section{Correction} Dose-response comparison of ipratropium bromide from a
metered-dose inhaler and by jet nebulisation

In the paper by SA Gomm and others (April, pp 297-301) we regret an error in line 3 of the last paragraph, where "< 45\%" should be "> $45 \%$." 